\title{
1 \\ DIVISÃO DO TRABALHO SOCIAL E \\ ARRANJOS PRODUTIVOS LOCAIS: REFLEXOS ECONÔMICOS DE EFEITOS MORAIS DE REDES INTERORGANIZACIONAIS
}

GUSTAVO MIELO SILVA

Doutor em Sociologia pelo Departamento de Sociologia e Antropologia da Universidade Federal de Minas Gerais (UFMG).

Professor do Departamento de Ciências Administrativas e Contábeis da Universidade Federal de São João del-Rei (UFSJ). Avenida Visconde do Rio Preto, s/n, campus CTAN, prédio direito, sala 2.27, Colônia do Bengo São João del-Rei - MG - Brasil - CEP 36300-000 E-mail: gustavomelosilva@yahoo.com.br

\section{JORGE ALEXANDRE BARBOSA NEVES}

Doutor em Sociologia pelo Departamento de Sociologia da Universidade de Wisconsin (Madison, WI, Estados Unidos). Professor do Departamento de Sociologia e Antropologia da Universidade Federal de Minas Gerais (UFMG). Avenida Antônio Carlos, 6.627, Pampulha - Belo Horizonte - MG - Brasil - CEP 31 270-901 E-mail: jorgeaneves@gmail.com 


\section{RESUMO}

Este artigo utiliza um recorte teórico que evidencia fatos sociais, especificamente da divisão do trabalho social, que atuam diretamente na eficiência de organizações, por meio da coesão e da solidariedade. Entretanto, essa leitura da realidade socioeconômica não vem sendo utilizada em sua plenitude para a compreensão da imersão social de redes interorganizacionais territorializadas, ou seja, de arranjos produtivos locais. Pode-se perceber que uma das principais características competitivas, denominadas atuais dentro do discurso empresarial e até mesmo de políticas de desenvolvimento econômico, é a necessidade de as empresas atuarem de forma conjunta e associada em determinados territórios, sejam estes distritos industriais, regiões, municípios ou cidades. Portanto, a aglomeração é uma possibilidade concreta para o desenvolvimento empresarial a partir de estruturas organizacionais baseadas na associação, complementariedade, compartilhamento, troca e ajuda mútua, que têm como referência as redes, que também compõem a estrutura social de mercados e reforçam a discussão sociológica de que a competição também gera a solidariedade. As ações econômicas individuais não estão livres de pressões estruturais e suscetíveis de ser interpretadas dentro da lógica puramente aditiva e mecânica da agregação. As pressões estruturais que pesam sobre a ação econômica não se reduzem às necessidades inscritas, em dado momento do tempo, nas disponibilidades econômicas imediatas ou na instabilidade das interações. Os interesses econômicos de mercado estão, para a nova sociologia, econômica imersos em redes pessoais e de grupos sociais. O mercado, portanto, não se constitui de organizações isoladas, como nos modelos de concorrência perfeita da ciência econômica, mas de aglomerados organizacionais que formam uma estrutura social.

\section{PALAVRAS-CHAVE}

Arranjos produtivos locais; Produção territorial; Divisão do trabalho social; Relações sociais; Estrutura social. 


\section{INTRODUÇÃO}

As relações econômicas não são precedentes de outros tipos de relações que representam fatos sociais, como coesão, confiança e solidariedade. Os mercados só operam bem quando estão sustentados por redes sociais compostas de laços individuais polivalentes, em que as atividades econômicas no longo prazo requerem dessas redes confiança entre os indivíduos e organizações. Portanto, no contexto do fenômeno organizacional, o tipo de capital social frequentemente mais útil é a capacidade de formar novas associações e cooperar dentro dos termos de referência que uma comunidade ou grupo estabelecem. Esse tipo de grupo é baseado em valores compartilhados, que foram disseminados pela complexa divisão do trabalho da sociedade industrial. Essa sociabilidade espontânea refere-se a uma ampla gama de comunidades intermediárias distintas da família ou das estabelecidas deliberadamente por governos.

Diante da realidade social contemporânea, é um equívoco sustentar que o elemento de ordem que efetivamente existe em uma sociedade diferenciada com ampla extensão de relação de troca possa derivar dos interesses imediatos das partes nessas relações. Nesse sentido, conforme Durkheim (I999), a diferenciação social é resultado do aumento do número e da densidade da sociedade, ou seja, uma pressão demográfica, mas que também é moral pela necessidade das relações econômicas, por exemplo, de coesão e confiança entre as partes que intermediam trocas econômicas. A divisão do trabalho social (DTS) ocorre mediante a diferenciação de áreas distintas, dentro das quais diversos grupos de indivíduos estão em mútua competição. Cada indivíduo, no lugar de competir diretamente com todos os demais, só compete com número limitado de indivíduos, no mesmo grupo ocupacional (DURKHEIM, I999).

O processo de divisão do trabalho na sociedade é um tema de interesse de autores como Smith (1996) e Marx (1985), entretanto a abordagem por esses autores é distinta da que foi utilizada neste trabalho. Smith (I996) destaca que a divisão do trabalho aumenta a habilidade e a destreza do operário, o que proporciona economia do tempo de produção de um trabalho, que é facilitado e abreviado com a utilização de máquinas adequadas, que conjuntamente permitem atividades econômicas mais eficientes, que, por sua vez, são limitadas pela extensão do mercado. Conforme Marx (I985), a divisão do trabalho estimula a cooperação como forma de trabalho em que muitos trabalhadores juntos, de acordo com um plano, no mesmo processo de produção ou em processos de produção diferentes estão conectados. Portanto, para Marx (I985), o trabalhador coletivo constitui o mecanismo vivo da manufatura de trabalhadores parciais e limitados, que produzem em menos tempo e que aperfeiçoam o método de trabalho 
parcial e proporcionam excedentes econômicos que são apropriados pelos donos dos meios de produção. Entretanto, a abordagem da sociologia econômica de Durkheim (I999) nos permitiu analisar como relações sociais promovem e proporcionam, por meio da coesão e confiança necessárias entre empreendedores e seus empreendimentos, o desenvolvimento de atividades econômicas entre atores que possuem laços e contratos sociais em determinados territórios.

A realidade atual das atividades econômicas pode ser caracterizada como uma sociedade industrial organizada em territórios divididos e especializados, o que reforça não apenas a individualidade de indivíduos e organizações, mas também aumenta a solidariedade entre aqueles que pertencem a arranjos produtivos locais (APL). As redes de cooperação e os APL são considerados como uma estratégia de organização de sistemas produtivos territorializados e assumem papel determinante nas novas abordagens do desenvolvimento econômico local. Vale ressaltar que tanto aspectos econômicos como sociais interferem na eficiência e eficácia de arranjos organizacionais e no desenvolvimento local. Por exemplo, por um lado, o volume e o perfil da demanda interferem na eficiência, e, por outro lado, a existência de laços sociais ou até mesmo de instituições interfere na eficácia de arranjos organizacionais e do desenvolvimento local. A compreensão e as análises sobre os reflexos do desenvolvimento e da modernização econômica tiveram sangue novo com estudos sobre as características sociais dos sistemas de produção territorializados (CONTI, 2005). Entretanto, essas abordagens sobre APL não contemplam análises socioeconômicas que permitem compreender a dinâmica de uma relação interorganizacional que inicialmente pode ser definida como paradoxal, de acordo com Durkheim (I999), de diferenciação como fonte de solidariedade em sistemas produtivos territorializados.

Este artigo faz uma reflexão sobre fundamentos sociais, como a coesão de grupos e a confiança e solidariedade entre seus componentes como fatores determinantes para o sucesso desses arranjos interorganizacionais em territórios. Esse recorte teórico não vem sendo utilizado em sua plenitude para a compreensão da imersão social de um APL em uma realidade socioeconômica territorial. Para tanto, vamos inicialmente apresentar algumas bases conceituais da sociologia econômica que são referências sobre os reflexos econômicos de efeitos morais da divisão do trabalho social, o que ajudará na reflexão das bases sobre as quais esta gera solidariedade por meio da competição. Nesse sentido, a produção territorial pode ser considerada uma expansão da divisão do trabalho industrial, que confirma realidades da vida cotidiana em organizações que representam relações sociais em mercados por meio de vínculos entre atores sociais em redes interorganizacionais. 


\section{RELAÇÕES SOCIAIS NOS MERCADOS: AÇÃO ECONÔMICA E AÇÃO COLETIVA}

A ação racional é um ponto central das abordagens econômica e sociológica que buscam compreender como são as escolhas de indivíduos em mercados, que, por sua vez, são estruturados por meio de redes de relacionamentos sociais que organizam a vida econômica. Para a sociologia, o mercado é uma construção social caracterizada por conflitos, dependências, estruturas e imprevisibilidades. O mercado é, conforme Abramovay (2009), o contrário da autonomia individual, já que pode ser compreendido a partir de grupos que, por meio da cooperação, alcançam seus objetivos funcionais, enquanto a divisão do trabalho avança para atender às pressões sociais externas aos indivíduos, que são inerentes à complexidade da construção social de mercados que possuem estruturas e não são simplesmente um ponto de encontro de atores anônimos, impessoais e que se relacionam de maneira efêmera.

O mercado é influenciado por uma realidade que emerge do contexto social, por exemplo, conforme Granovetter (2002), por meio de costumes, hábitos ou normas. A realidade do mercado pode ser observada sociologicamente por meio de ações e interações que os indivíduos procuram permanentemente dotar de significado (ABRAMOVAY, 2009). Além do indivíduo, grupos, relações sociais e outras variáveis, como gosto, conhecimento, educação, etnia e família, podem influenciar a ação econômica e os interesses individuais (GRANOVETTER, 2002).

As ações econômicas não acompanham somente os caminhos concisos e diretos da maximização, mas também os caminhos consideravelmente mais complexos das relações sociais. Os economistas estão equivocados, mas não tanto por conta de razões psicológicas correlacionadas ao homo economicus ou, de fato, por quão racionais são ou não as pessoas, mas pelo não reconhecimento da importância da estrutura social da economia (SWEDBERG, 2004). As perspectivas analíticas econômicas geralmente não têm contribuído para compreender como preferências são formadas, assumidas e o que justificaria as mudanças substanciais que ocorrem no mercado ao longo do tempo. O interesse principal dessa perspectiva é compreender o comportamento humano no mercado de indivíduos anônimos. Entretanto, o homo economicus quando age faz uso de informações que possui e identifica na sociedade e que estão expressas em suas decisões de mercado.

As atitudes do homo economicus são influenciadas por aspectos coletivos que interferem na maximização de seus lucros. Esses aspectos, não econômicos, afetam o comportamento e a racionalidade humana. A racionalidade humana 
sobre a vida econômica é influenciada pela evolução e pelo comportamento das sociedades, portanto aspectos não econômicos são fundamentais para a compreensão do comportamento humano e do mercado. A racionalidade humana e institucional considera, conforme Granovetter (2002), as relações sociais não só a partir das transações econômicas que são definidas por cálculos racionais com o objetivo de obtenção do lucro individual. A racionalidade é influenciada por processos que continuamente são construídos e reconstruídos na realidade da interação entre indivíduos e grupos sociais no mercado. A racionalidade individual não é apenas influenciada por grupos em contextos sociais presentes, mas também por outros grupos em outros momentos históricos. As relações sociais possuem arranjos institucionais ou moralidades que estão presentes na produção e na economia por meio da racionalidade individual imersa em relações sociais (GRANOVETTER, 2002).

O mercado é um fato social que a sociologia econômica busca compreender especificamente a partir da estrutura das redes sociais que influenciam a ação coletiva com a geração e com o contexto cultural do mercado. A ação econômica é influenciada por aspectos racionais e político-econômicos que definem restrições de recursos escassos em estruturas sociais. A economia é parte integrante da sociedade, que é sua base de referência e pode ser analisada a partir de descrições e explanações feitas a partir de métodos históricos comparativos. O modelo sociológico pressupõe que a ação econômica individual é influenciada por padrões institucionais, por induções estruturais e pelo desenvolvimento social, que tem como resultados índices institucionais que consequentemente influenciam a racionalidade humana e ajustam os padrões institucionais iniciais (SMELSER; SWEDBERG, I994).

As ações econômicas individuais não estão livres de pressões estruturais e suscetíveis de ser interpretadas dentro da lógica puramente aditiva e mecânica da agregação. As pressões estruturais que pesam sobre a ação econômica não se reduzem às necessidades inscritas, em dado momento do tempo, nas disponibilidades econômicas imediatas ou na instabilidade das interações. Para Bourdieu (2005a, 2005b), existe um campo econômico, uma estrutura social, em que estão inscritas as disposições sobre a ação econômica, seja na determinação dos preços, seja na definição das estratégias publicitárias. O sujeito e sua decisão econômica não se configuram como um indivíduo isolado, mas como um ator coletivo, seja um grupo profissional, familiar ou empresarial, que funciona como um campo. Este pode estar profundamente enraizado no passado sob a forma de disposições, rotinas ou por meio da história dos atores sociais (BOURDIEU, 2005a, 2005b).

A ação econômica, na maioria das vezes, está integrada a um sistema complexo de estratégias de reprodução social, portanto plenas da história de tudo ao 
que visa perpetuar. Conforme Bourdieu (2005a), dimensões inteiras da existência humana e, em particular, as esferas da família, arte ou literatura, ciência e, mesmo em certa medida, da burocracia permanecem, pelo menos em grande parte, estranhas à busca da maximização dos lucros materiais. Para Bourdieu (2005a), o campo econômico só existe por meio de indivíduos que agem economicamente e possuem vínculos com outros indivíduos, o que confere ao campo uma estrutura de relações sociais. A ação econômica é dotada de subjetividade, produto da história coletiva e individual. No campo econômico, que também pode ser compreendido como estrutura, a racionalidade instrumental é limitada por sua imersão social (BOURDIEU, 2005a).

A análise de mercados como construções sociais pode, entretanto, ser realizada a partir das relações entre atores e grupos, e não somente por meio das normas e regras institucionalizadas. Conforme Raud-Mattedi (2005b), a sociologia econômica, a partir da década de I970, retoma a análise sociológica do núcleo da vida econômica, ou seja, o mercado, que é considerado como uma estrutura social. Granovetter (2002) retoma a abordagem sociológica dos fenômenos econômicos com discussões que mostram a influência das relações sociais na ação, nos resultados e nas instituições econômicas e impulsionam os estudos com conceitos fundamentais para a análise da vida econômica como rede e imersão.

Nessa perspectiva de troca social, a análise de redes de relacionamento tem como vantagem, conforme Swedberg (2004), o fato de constituir uma ferramenta flexível por meio da qual se pode lidar com um número considerável de fenômenos sociais e econômicos do mercado. A análise de redes tem sido usada, por exemplo, para explorar diversos tipos de interações econômicas que não podem ser classificadas nem como costumes nem como algum tipo de organização econômica. Essas formas sociais intermediárias são, por vezes, referidas como formas de organização em rede (SWEDBERG, 2004). Entretanto, pouca atenção teórica vem sendo dada ao processo de diferenciação produtiva e de solidariedade entre os atores socias da rede.

\section{DIVISÃO DO TRABALHO SOCIAL: DIFERENCIAÇÃO E SOLIDARIEDADE}

Segundo Durkheim (1999), a divisão do trabalho normal supõe que o trabalhador debruçado sobre sua tarefa não perca de vista seus colaboradores, aja sobre eles e sofra sua ação. Os serviços econômicos que a divisão do trabalho social (DTS) pode prestar são relativamente menores em comparação ao efeito moral que ela produz, e sua verdadeira função seria criar, entre dois ou vários indivíduos 
ou organizações, um sentimento de solidariedade. O efeito da divisão do trabalho não é aumentar o rendimento das funções divididas, mas torná-las solidárias (DURKHEIM, I999). Na sociedade dividida pelo trabalho e regulada pelo contrato social, o papel da moral é permitir a realização e adequação entre os interesses individuais e coletivos. As regras morais são fundamentais para a estabilidade da sociedade, uma vez que asseguram o respeito às instituições básicas. Essas instituições, por sua vez, asseguram a confiança no mercado, mesmo entre pessoas que não se conhecem diretamente, pelo respeito aos maiores valores fundamentais da sociedade moderna, ou seja, os direitos individuais (RAUD-MATTEDI, 2005a).

Durkheim (I999) considera que os indivíduos perseguem seus próprios interesses com harmonia social, que deriva essencialmente da divisão do trabalho e consiste em uma cooperação que se produz automaticamente. Essa perspectiva durkheimiana considera que ameaças à harmonia social podem ser ajustadas por atores sociais como o Estado e as corporações profissionais. Como veremos mais à frente, as organizações sociais territoriais também podem ter o papel social de ajustar ou até mesmo regular as relações econômicas entre os interesses individuais e coletivos ou privados e públicos.

Para Durkheim (I999), basta que cada indivíduo se consagre a uma função especial para se encontrar solidário aos outros papéis na organização industrial. O interesse individual de se consagrar a determinada função e conviver em harmonia com as demais funções exercidas por indivíduos distintos indica a existência implícita de normas e regras sociais que influenciam o comportamento humano. Para que os indivíduos cooperem, não basta à relação o sentimento de dependência, mas torna-se necessário que direitos e deveres sejam estabelecidos, por exemplo, por meio de relações contratuais. Essas condições são fatores coletivos e determinam a ação social dos indivíduos (DURKHEIM, I999).

A relação econômica com o progresso da DTS também é definida pela pressão social de os indivíduos sentirem realmente a necessidade de produtos mais abundantes e de valor econômico unitário mais acessível. Além dos aspectos de volume e densidade social e do atendimento de necessidades de consumo, conforme Durkheim (1999), para grupos sociais serem organizados a partir do trabalho, torna-se necessário um sistema desenvolvido de regras formais e informais que predeterminam o funcionamento tanto individual como coletivo. Assim, à medida que o trabalho se divide, constituem-se uma moral e uma multidão de direitos profissionais; no entanto, essa regulamentação não deixa menos ampliada a esfera de ação do indivíduo (DURKHEIM, I999). O que constitui, portanto, a unidade das sociedades organizadas a partir da divisão do trabalho é o consenso espontâneo entre as partes. A solidariedade interna dessa construção 
social dos mercados é indispensável também como ação reguladora que pode faltar em alguns casos considerados pelo autor como anômicos, mas que é condição necessária para a DTS normal. Nesse sentido, Durkheim (I999) avança em uma perspectiva institucional de que a garantia do espírito de conjunto e do sentimento de solidariedade comum demanda um ator qualificado para exercê-lo. Esse papel seria do Estado moderno, entretanto o autor o considera um ator geral em demasia para assegurar o concurso das funções sociais que este não realiza.

Durkheim (I999), com o seu estudo sobre a DTS, apresenta uma clara ordenação lógica que mostra como o volume e densidade populacional e moral, a preservação da individualidade e a regulação social são fatores fundamentais para que a diferenciação gere a solidariedade e não o conflito no mercado. Entretanto, instituições entre o Estado e o indivíduo devem garantir seus deveres e direitos. Conforme Raud-Mattedi (2005a), Durkheim reflete sobre o papel das instituições na orientação do comportamento do ator econômico e, portanto, na regulação do mercado, com conclusões frequentemente semelhantes. Entretanto, mesmo Durkheim (I999) reconhecendo as regras informais dos contratos, ele não explicita na DTS as relações econômicas que podem ser reguladas sem que o Estado ou corporações exerçam seus papéis institucionais por meio de contratos formais entre os indivíduos para a construção social do mercado.

Segundo Durkheim (I999), o incremento da atividade funcional reflete no aumento de solidariedade, pelo fato de que as funções de um organismo só podem tornar-se mais ativas se também se tornarem mais contínuas. Ou seja, um organismo em particular nada pode fazer sem o concurso dos outros; só pode produzir mais se os outros também o fizerem. O rendimento desses só pode aumentar, por seu turno, se o do precedente elevar mais uma vez, por uma nova reação. Toda maior quantidade de atividade de uma função, por implicar aumento correspondente das funções solidárias, implica um novo aumento da primeira, o que só é possível se esta se tornar mais contínua. É claro que essas reações não se produzem indefinidamente, mas chega um momento em que o equilíbrio torna a se estabelecer. E, nesses casos, o trabalho torna-se mais contínuo à medida que se divide. Portanto, a DTS é fonte de coesão social não apenas por tornar os indivíduos mais solidários, mas porque limita a atividade de cada um e também a aumenta (DURKHEIM, I999). Mas a regulação ocorre somente no interior das organizações industriais? Atualmente, como veremos nas próximas seções deste artigo, ela também é discutida na coordenação das indústrias territorialmente localizadas e concentradas, que podem representar socialmente uma expansão da DTS. 


\subsection{MERCADO DE PRODUÇÃO TERRITORIAL: REFLEXOS ECONÔMICOS DE CONSEQUÊNCIAS MORAIS}

Conforme Conti (2005), a compreensão do desenvolvimento e da modernização econômica pode ser realizada a partir de análises das características dos sistemas de produção territorializados, por um lado, no município, como esfera autônoma da organização político-administrativa do país, mas, por outro, também como consciência associativa de participação da vida política da comunidade local. E, na ideia de capital social, ou seja, o estoque de valores e comportamentos coletivos, expressos por dada comunidade, como ingredientes fundamentais para seu desenvolvimento e modernização. A imersão territorial dos atores pode fomentar a competitividade no sistema local com a implantação de hábitos, convenções e normas de comportamento, que são estimulados por meio da proximidade geográfica, que transcendem as tradicionais relações cliente-fornecedor e proporcionam a formação de redes estratégicas formais e informais de colaboração e interação. Essas redes se formam por meio de mercados locais de trabalho, convenções e regras formuladas para o desenvolvimento de relações e conhecimento empresarial (CONTI, 2005).

Nos arranjos produtivos locais (APL), o sucesso econômico de cada organização passa a depender de sua capacidade de especialização naquilo que consegue estabelecer vantagens comparativas efetivas e dinâmicas que são decorrentes, conforme Diniz, Santos e Crocco (2006), do estoque de atributos e da capacidade contínua de inovação, que leva países e localidades, ou seja, territórios, à criação de organizações locais para sua promoção, como os parques e as incubadoras tecnológicos. Para Lemos (2006), a relação entre economia e geografia só adquiriu relevância na teoria econômica em um período relativamente recente. Essa realidade é observada por meio de sistemas de produção territorializados que têm, conforme Suzigan, Garcia e Furtado (2005), nas economias externas locais o cerne da discussão de clusters, porque são elas que determinam a própria existência da aglomeração ao proporcionarem custos reduzidos para organizações aglomeradas.

Os trabalhos de Gereffi (I994), Gereffi, Korzeniewicz e Korzeniewicz (I994), Piore e Sabel (I984) e Raynolds (I994) podem ser considerados uma continuidade da abordagem sobre o fenômeno econômico da divisão do trabalho social, que tem como consequência econômica a organização em redes produtivas territorializadas. Esse processo também é decorrente de uma realidade de produção em massa e de flexibilização produtiva de pequenas organizações integradas em redes que dependem de cooperação e também de competição (PIORE; SABEL, I984; RAYNOLDS, I994). A rede de produção é, conforme Gereffi, Korzeniewicz 
e Korzeniewicz (I994), um novo paradigma organizacional que permite mais adequadamente a formulação estratégica de ligamentos, correlações de processos entre micro e macroestruturas sociais dentro de unidades de análises de contextos globais, nacionais e locais. Vale ressaltar que, por um lado, a eficiência econômica é dependente da eficácia da ação coletiva, ou seja, para que as organizações em seu arranjo produtivo local sejam eficientes, estas dependem da existência de coesão e confiança entre as partes. Por outro lado, a eficácia da ação coletiva cristalizada em redes organizacionais pode reduzir o custo de transação entre as partes de uma rede e consequentemente gerar eficiência econômica tanto de uma organização como de toda uma rede organizacional de um arranjo produtivo local (APL).

Essas redes estabelecem maior coordenação entre as organizações de determinados setores com todo o ambiente institucional. Os fatores de sucesso nas economias industriais em redes estão no fato de que estas possibilitam redução de custos de aquisição e promoção de espécie de regulação de territórios, o que faz que a cooperação preceda à competição (BAIARDI; LANIADO, 2006). Entretanto, além de considerarem as organizações empresariais, essas redes são estruturas sociais, e, no seu interior, estão imersos outros atores sociais e políticos relevantes em cada situação concreta, portanto o traço central de análise de redes está nas relações entre atores sociais. Esses atores sociais também defendem seus interesses individuais e, para alcançá-los, têm como parte da estrutura dos mercados a organização social de suas unidades industriais divididas e especializadas.

Por exemplo, em algumas regiões da Itália, o desenvolvimento econômico só foi possível a partir da coesão e solidariedade expressas no engajamento cívico de sua população, que foi um diferencial, conforme Putnam (2005), do desenvolvimento desses territórios. Um marco de reconhecimento das individualidades regionais foi a proposição e execução de uma nova divisão de autoridade entre o centro e as demais regiões via os governos regionais com suas identidades, que passaram a ter autonomia, o que ocorreu nesse país no final da década de I970, especificamente após I976. As decisões políticas tiveram sua ênfase nas comunidades e não em particularidades de alguns indivíduos que as povoavam, o que valorizou a vida coletiva e fortaleceu as individualidades regionais (PUTNAM, 2005).

O que ocorreu na prática do desenvolvimento desse território foi, conforme Putnam (2005), a formação de densa rede de associações secundárias, que incorporaram e promoveram, ao mesmo tempo, a colaboração social e ligaram o Estado aos indivíduos. Nesse aspecto, é possível, de acordo com Durkheim (I999), que a construção social do mercado nesse território italiano ocorreu por meio de densas redes de associações, que foram instituições corresponsáveis pela proteção e satisfação dos direitos individuais e, portanto, reguladoras desse mercado. 
O caso italiano é um marco indicativo básico do engajamento de indivíduos e sociedade e foi denominado por Putnam (2005) sociabilidade cívica, nos distritos industriais italianos descentralizados territorialmente e imersos nos interesses de indivíduos e da sociedade. Putnam (2005) observou que as empresas competiam acirradamente no campo da eficiência e da inovação em produtos, mas também cooperavam nos serviços administrativos, na aquisição de matérias-primas, no financiamento e na pesquisa, portanto existia eficácia da ação coletiva. Essas organizações empresariais combinavam baixa integração vertical de suas cadeias produtivas e alta integração horizontal de seus empreendimentos, subcontratando para trabalhos extras concorrentes temporariamente subempregados. Essa realidade socioeconômica contribuiu para a estruturação de vasta rede de associações econômicas privadas e de organizações políticas, que promoveram a cooperação e propiciaram às pequenas empresas a infraestrutura que elas sozinhas não teriam como obter no mercado (PUTNAM, 2005).

Conforme Haddad (2004), os distritos industriais italianos foram formados por grupos de empresas altamente concentradas do ponto de vista geográfico, ou seja, dos seus mercados de produção territorial, as quais trabalham, direta ou indiretamente, para o mesmo mercado consumidor, compartilhando valores e conhecimentos que definem um ambiente cultural e que são especificamente interligados num mix de competição e cooperação. A realidade desse território italiano, formado por empresas individuais e por distritos industriais, que representam redes associativas do mercado de produção, chama a atenção para o aumento de densidade, nesse caso não somente populacional, mas especificamente da densidade de unidades produtoras que, para coexistirem no mercado consumidor em que competem por eficiência, estimulam a divisão do trabalho e promovem, por meio do convívio social associativo, a eficácia da ação coletiva.

Pode-se perceber que uma das principais características competitivas, denominadas atuais dentro do discurso empresarial e até mesmo de políticas de desenvolvimento econômico, é a necessidade de as empresas atuarem de forma conjunta e associada em determinados territórios, sejam estes distritos industriais, regiões, municípios ou cidades. Essa suposta modernidade e essa atualidade vêm estimulando políticas de promoção do desenvolvimento socioeconômico de territórios, especificamente denominados arranjos produtivos locais. Entretanto, Durkheim (I999) discutia e refletia na DTS que as diferentes cidades tendem cada vez mais a certas especialidades, de tal modo que foram distinguidas em cidades universitárias, de funcionários, de fábricas, de comércio, de águas e de gente que vive de rendas. Em certos pontos ou certas regiões, concentram-se grandes indústrias de construção de máquinas, fiações, manufatureira de tecidos, curtumes, altos-fornos e indústria açucareira, que trabalham para todo o país. Aí se estabelecem escolas especiais, a população operária se instala e a 
construção de máquinas se concentra, enquanto as comunicações e a organização do crédito se acomodam às circunstâncias particulares e específicas de mercados e territórios.

Portanto, temos que a aglomeração é uma possibilidade concreta para o desenvolvimento empresarial a partir de estruturas organizacionais baseadas em associação, complementaridade, compartilhamento, troca e ajuda mútua, que têm como referência as redes, que também compõem a estrutura social de mercados e reforçam a discussão durkheimiana de que a competição também gera a solidariedade. As redes reforçam o conceito de colaboração mútua, a fim de que as empresas individualmente possam sobreviver e se manter competitivas no mercado internacional. Entretanto, as análises atuais de redes priorizam uma análise técnico-econômica em detrimento de uma análise das relações sociais em atividades econômicas que, antes de serem da esfera da economia, pertencem à vida social. As análises técnicas dão ênfase ao impacto do paradigma microeletrônico como alavanca para o desenvolvimento dessas redes, principalmente pelo potencial de integração via o barateamento e a rapidez das comunicações. É importante salientar que até mesmo o impacto das comunicações como fator de ligação entre regiões inicialmente distantes e de estímulo à divisão do trabalho também é discutido por Durkheim (I999), quando este considera que uma região, até então independente de um centro industrial, pode ser ligada a ele por via de comunicação que suprime parcialmente a distância geográfica. Portanto, para esse autor, de imediato uma das barreiras que detinham o desenvolvimento de uma região é retirada ou, pelo menos, recua. O mercado amplia-se com a existência de mais necessidades a satisfazer. Um novo aumento da população e a densidade industrial criam as bases para uma nova dinâmica da concorrência, sendo necessário existir, em algum lugar, ou uma eliminação ou uma nova diferenciação (DURKHEIM, I999). Como podemos perceber, o sucesso de arranjos organizacionais territorrializados não está somente ancorado em aspectos de viabilidade tecnológica da comunicação ou do atendimento econômico de necessidades de consumo. Mesmo no final do século XIX, Durkheim (I999) observou que aspectos econômicos e tecnológicos não suprimiam a relevância de aspectos como a coesão e a confiança entre atores sociais. A solidariedade entre os membros de um território em busca do desenvolvimento social estimulava tanto o desenvolvimento tecnológico como o econômico.

No entanto, o aumento das necessidades do mercado a serem satisfeitas propicia e fomenta a DTS, que consequentemente tem como resultado a multiplicação das organizações industriais e comerciais em territórios produtivos. Entretanto, para que as unidades sociais possam diferenciar-se, é necessário antes de qualquer coisa que sejam atraídas ou agrupadas em virtude das semelhanças que apresentem. A vida coletiva não nasceu da vida individual, mas, ao contrário, foi a 
segunda que nasceu da primeira. É apenas sobre essa condição que se deve explicar como a individualidade pessoal das unidades sociais pôde formar-se e crescer sem desagregar a sociedade. Para que a divisão do trabalho possa nascer e crescer, não basta que existam nos indivíduos germes de aptidões especiais, nem que eles sejam estimulados a variar no sentido dessas aptidões, mas é necessário, além disso, que as variações individuais sejam possíveis (DURKHEIM, I999).

\subsubsection{Realidade atual dos estudos sobre arranjos em redes interorganizacionais}

O enfoque dado em estudos recentes sobre APL (AMATO NETO, 2000; CROCCO et. al., 2006; CASSIOLATO; LASTRES, 2002; SOUZA; SOUZA, 2004; SUZIGAN; CÉRRON; DIEGUES JUNIOR, 2005; SUZIGAN; GARCIA; FURTADO, 2005; SUZIGAN; GARCIA; FURTADO, 2007) não aborda ou aborda de forma superficial como efeitos morais geram reflexos econômicos em redes interorganizacionais, como foi salientado nas seções anteriores.

Segundo Suzigan, Cérron e Diegues Junior (2005), o ponto fundamental a ser discutido atualmente, tanto sobre o fomento como acerca do desenvolvimento das aglomerações produtivas, é a coordenação dos sistemas locais de produção e inovação que tem papel importante, explicitado, por exemplo, em aspectos referentes à formação de profissionais especializados, à promoção de cursos de geração e treinamento de mão de obra qualificada, ao desenvolvimento de pesquisas científicas e tecnológicas, à prestação de serviços especializados de assistência técnica, de prospecção e difusão de informações, e ao desenvolvimento de tecnologias.

Suzigan, Garcia e Furtado (2007) entendem a governança de arranjos ou sistemas produtivos locais como a capacidade de comando ou coordenação que certos agentes (empresas, instituições ou, mesmo, um agente coordenador) exercem sobre as inter-relações produtivas, comerciais, tecnológicas e outras, influenciando decisivamente o desenvolvimento do sistema ou arranjo local. A complexidade da governança decorre, por um lado, do difícil equilíbrio entre cooperação e competição no âmbito do APL e, por outro, dos fatores sociais que condicionam a governança. Portanto, isso implica dizer que não existem modelos de aplicação genérica para a governança de APL. Antes de qualquer outra consideração, é preciso deixar claro que a questão da governança em APL só se coloca quando os agentes locais procuram ir além do aproveitamento das vantagens competitivas locais decorrentes de economias externas da aglomeração e tentam tomar iniciativas coletivas ou desenvolver ações conjuntas que estreitem suas interdependências no sentido de alcançar a eficiência coletiva (SUZIGAN; GARCIA; FURTADO, 2007). 
As iniciativas ou ações conjuntas podem ter vários objetivos, mas de modo geral, entre outras coisas, buscam a formação de centrais de compras de insumos, consórcios de exportação, centros tecnológicos de uso coletivo, criação de instituições de ensino e formação profissional, criação de marca de denominação local, desenvolvimento de redes ou sistemas próprios de distribuição. Suzigan, Garcia e Furtado (2007) definem como fatores condicionantes da governança local, tendo como referência as experiências de Franca (SP) e do Vale do Rio dos Sinos (RS), uma efetiva divisão do trabalho e cooperação entre empresas. A confiança necessária para a governança local do APL é consequência do forte espírito associativo e das interações de empresas e instituições, e também de traços socioculturais que emergem de práticas historicamente enraizadas de cooperação informal entre as empresas (SUZIGAN; GARCIA; FURTADO, 2007).

A descentralização da grande corporação industrial e a especialização de pequenas e médias empresas não foram o foco das reflexões de Durkheim (I999), entretanto trata-se de um aspecto do fenômeno socioeconômico em curso que chama a atenção de Amato Neto (2000). Mas a confiança entre os atores sociais para a efetivação do processo de especialização definido por Amato Neto (2000) como de extrema importância confirma aspectos fundamentais da sociologia econômica de Durkheim (I999). O aumento da concentração e respectivamente da densidade moral das relações econômicas entre organizações, aspecto já abordado por Durkheim (I999), é o foco da análise da concentração de empresas em territórios brasileiros, o que, para Crocco et al. (2006), explicam em boa medida o desempenho econômico dessas aglomerações, entretanto as consequências econômicas não foram objeto das reflexões de Durkheim (I999).

Outro avanço recente sobre a divisão do trabalho social em territórios não abordada por Durkheim (I999) está nos estudos de Cassiolato e Lastres (2002) e de Souza e Souza (2004) que, por um lado, confirmam a tese durkheimiana de que o processo de divisão do trabalho social proporciona também solidariedade e não somente a possibilidade do conflito de interesses. Por outro lado, Souza e Souza (2004) apontam que as redes de empresas se configuram como formas de organização econômica com o objetivo de aprimoramento tecnológico e gerencial.

Para Amato Neto (2000), as análises econômicas enfatizam a descentralização da grande corporação e a especialização de pequenas e médias empresas. O aumento da vida econômica, ou seja, o aumento das necessidades a serem satisfeitas, gera a necessidade de novas funções ajustadas que fomentam a divisão do trabalho social, e consequentemente as organizações se multiplicam. Para que as unidades sociais possam diferenciar-se, é necessário antes de qualquer coisa que sejam atraídas ou agrupadas em virtude das semelhanças que apresentem. Portanto, as redes são caracterizadas nas análises econômicas e organizacionais como sendo compostas geralmente de pequenas empresas independentes, que 
são organizadas em um local ou região como base e geralmente pertencentes ao mesmo setor industrial. Empresas individuais especializadas em uma fase particular do processo produtivo, organizadas de forma conjunta e que valorizam as instituições locais por meio de relacionamentos de competição e cooperação. Para Amato Neto (2000), outra denominação para esses coletivos empresariais territoriais é clusters regionais e setoriais. Estes são caracterizados como concentrações de empreendimentos que geram eficiência coletiva, uma consequência dos seguintes fatores: divisão do trabalho e especialização entre os produtores; estipulação da especialidade de cada produtor; surgimento de fornecedores de matéria-prima e máquinas; agentes que vendem para mercados distantes; empresas especialistas em serviços tecnológicos, financeiros e contábeis; classe de trabalhadores assalariados com qualificações e habilidades específicas; e associações para a realização de lobby e de tarefas específicas para o conjunto dos membros.

Para que a aglomeração de fato ocorra como uma realidade socioeconômica, conforme Amato Neto (2000), a confiança entre os atores é um fator determinante de sua formação, o que confirma mais uma vez uma condição durkheimiana das bases da solidariedade orgânica (DURKHEIM, I999). Existem várias realidades mundiais que são destacadas como experiências bem-sucedidas da aglomeração territorial ou, como Durkheim (I999) enfatiza, de densidade moral, que são, conforme Amato Neto (2000), as seguintes: redes de empresas especializadas na região central e noroeste da Itália; redes de pequenas e médias empresas e o distrito industrial do oeste da Alemanha; Keiretsus e os sistemas de subcontratação do Japão; redes de cooperação do Chile; redes de apoio às pequenas e médias empresas da Argentina; redes de apoio para a competitividade das pequenas e médias empresas do México.

A realidade do aumento e da densidade de concentração de empresas em territórios também vem sendo um fenômeno analisado no Brasil. A aglomeração é identificada por Crocco et al. (2006) pelo índice de concentração (IC) que classifica os municípios que possuem APL. Esse índice é composto por parâmetros como o número de empregos da atividade industrial, número de estabelecimentos e concentração de classes de indústrias. Para Crocco et al. (2006), os APL são entendidos como um município com alguma especialização específica, e, no caso brasileiro, identificam-se os seguintes arranjos por setores industriais: 99 no setor de couro e calçados; 64 no setor de metalurgia básica; 49 no setor de fabricação e montagem de veículos automotores; 48 no setor de fabricação de máquinas, aparelhos e materiais elétricos; I6 no setor de fabricação de material eletrônico, aparelhos e equipamentos de comunicação.

Para que possamos analisar os fenômenos sociais das aglomerações dessas indústrias individuais, torna-se necessário compreender como é a origem des- 
ses agrupamentos. Segundo Cassiolato e Lastres (2002), existem três tipos de origem de aglomeração identificados pela economia: industriais em setores tradicionais e artesanais, como aqueles produtores de sapatos, mobiliário, confecções, metalurgia etc.; complexos hi-tech, como o Vale do Silício, nos Estados Unidos; e os baseados na presença de grandes empresas, como em Baden-Wurttenburg, na Alemanha, e Seattle, nos Estados Unidos. Além de um tipo denominado aglomerações diversificadas - baseadas na especialização vertical; aglomerações decorrentes de subcontratação, ou seja, a especialização vertical e horizontal, em que a maior parte das empresas é dependente de uma grande empresa ou mais. Um papel fundamental para o desenvolvimento dessas aglomerações é o sistema de coordenação que estabelece as relações de caráter local entre empresas e instituições (CASSIOLATO; LASTRES, 2002).

As análises da origem dos agrupamentos nos levam a questões referentes aos fatores fundamentais para as aglomerações territoriais, que reafirmam condições durkheimianas para que a competição gere a solidariedade em vez de conflito. As redes organizacionais, conforme Souza e Souza (2004), se configuram como relações de cooperação entre pequenas e médias empresas com o intuito estratégico de aprimoramento tecnológico e gerencial, para melhoria de posicionamento competitivo. Para Durkheim (I999), o que faz com que qualquer aumento de atividade funcional determine um aumento de solidariedade é o fato de que as funções de um organismo só podem tornar-se mais ativas se também se tornarem mais contínuas. Ou seja, uma empresa em particular nada pode fazer sem o concurso das outras, só pode produzir mais se as outras também o fizerem. Mas o rendimento destas só pode aumentar, por seu turno, se o da precedente aumentar mais uma vez, por uma nova reação. Todo aumento de atividade de uma função, por implicar um aumento correspondente das funções solidárias, implica um novo aumento da primeira, o que só é possível se esta se tornar mais contínua. É claro que essas reações não se produzem indefinidamente, mas chega um momento em que o equilíbrio torna a se estabelecer. E o trabalho se torna mais contínuo à medida que se divide. Conforme Durkheim (I999), a divisão do trabalho social é uma fonte de coesão social, não apenas por tornar os indivíduos mais solidários ou porque limita a atividade de cada um, mas também porque a aumenta.

O desenvolvimento dos aglomerados produtivos tem impacto direto no desenvolvimento local de territórios. Portanto, as discussões de políticas de desenvolvimento regional e local vêm passando por execuções de projetos que têm como objetivo promover e articular os atores em arranjos produtivos locais independentes de como estão ligados a cadeias produtivas. Como visto na descrição dos estudos realizados sobre essas aglomerações, a ênfase até o momento foca uma perspectiva utilitarista e gerencial em detrimento de uma análise histórica e 
estrutural, e a divisão do trabalho social e as relações socioeconômicas poderiam auxiliar na explicação desses fenômenos socioeconômicos.

As aglomerações produtivas confirmam que os mercados são construções sociais que, a partir da DTS, têm importante fonte de solidariedade, fomentada pela competição de indivíduos, organizações e territórios. Entretanto, para a compreensão do mercado com uma construção social, devemos compreender a organização social como desafio para os APL e também como a ação coletiva e a estrutura social dos mercados. Portanto, para uma compreensão por meio de uma perspectiva sociológica da estratégia em organizações no mercado, não basta compreender a sociologia da divisão do trabalho, mas é preciso também compreender a sociologia da ação coletiva em mercados por meio de relacionamentos sociais.

\section{ESTRUTURA SOCIAL DO MERCADO: VÍNCULOS EM REDES SOCIAIS}

O foco de análise da rede é, conforme Smelser e Swedberg (I994), o processo econômico, suas conexões e interações entre economia e sociedade. O mercado é analisado como estrutura social e não simplesmente como processo racional instrumental de definição de preços ou como lugar físico de relações de troca, em que a competição e as informações são perfeitas e definidas em termos de demanda e suprimento. O mercado, portanto, para a sociologia econômica, consiste em relações sociais entre indivíduos que podem crescer e diminuir, dependendo das circunstâncias (SWEDBERG, I994).

Os interesses econômicos de mercado estão para a nova sociologia econômica imersos em redes pessoais e de grupos sociais. O mercado, portanto, não se constitui de empresas isoladas, como nos modelos de concorrência perfeita da ciência econômica, mas de aglomerados de empresas que formam uma estrutura social (SWEDBERG, I994). De acordo com Granovetter (I994), um ponto importante que distingue os grupos econômicos de simples aglomerados financeiros, como os conglomerados, é a existência de solidariedade social e de uma estrutura social entre as empresas que os compõem. Solidariedade essa que está imersa em laços ou vínculos sociais, como os familiares, de amizade ou étnicos. As redes sociais facilitam a circulação de informações e asseguram confiança ao limitarem os comportamentos oportunistas, já que o mercado tem estrutura social (GRANOVETTER, 2002).

A sociologia econômica revigorada por Granovetter (2002) resgata e revitaliza noções fundamentais de Polanyi (2000), de que a ação econômica é social- 
mente situada, portanto o ser humano não deixa de ser social com o homo ecomomicus, e o próprio sistema econômico é mera função da organização social. Polanyi (2000) chamou atenção para a existência estrutural de relações sociais no mercado por meio dos princípios de reciprocidade e redistribuição. Entretanto, a nova sociologia econômica analisa o papel de redes nas relações de troca mercantil, como instituições de redistribuição e coordenação que estruturam o mercado.

A análise de redes sociais considera as interações concretas entre indivíduos e grupos, trazendo respostas alternativas a uma série de problemas-chave da teoria econômica. Exemplo disso é o caso do mercado de trabalho, desenvolvimento econômico, êxito de micro e pequenas empresas, grupos econômicos, confiança e oportunismo, ou, ainda, da própria formação de preços, questão central da teoria neoclássica econômica. Para Swedberg e Granovetter (I992), a rede é um conjunto regular de contratos ou conexões sociais similares entre indivíduos e grupos. Por exemplo, o que Granovetter (I973) identifica no mercado de trabalho, em que é menos importante estar fortemente inserido em uma rede de amigos ou de parentes do que ter acesso, por meio de laços fracos, ou seja, de conhecidos, a várias redes. Os laços fracos são decisivos porque estabelecem pontes entre as redes, permitindo, assim, o acesso a universos sociais diversificados e a uma maior variedade de informações, que configuram a força dos laços fracos (GRANOVETTER, I973).

É importante salientar que as relações sociais não passam necessariamente por relações pessoais. A dimensão social das relações econômicas decorre do fato de que, no quadro da troca mercantil, os atores econômicos não levam em conta somente seus interesses próprios, mas também o contexto institucional, em particular as regras jurídicas, morais e tradicionais (RAUD-MATTEDI, 2005a).

Para a sociologia, a ação econômica é socialmente situada, e as instituições econômicas são construções sociais (GRANOVETTER, 2002; SWEDBERG; GRANOVETTER, I992). Essa afirmação significa que os indivíduos não agem de maneira autônoma, mas que suas ações estão imersas em sistemas concretos e contínuos de relações sociais. Portanto, as redes sociais permitem compreender, conforme Granovetter (2002), a imersão social das ações econômicas, em que, além de objetivos econômicos, os atores perseguem objetivos sociais, como a sociabilidade, o reconhecimento, o estatuto e o poder. As ações dos atores sociais são condicionadas ao fato de pertencerem a redes de relações interpessoais. O mercado, portanto, não consiste em um livre jogo de forças abstratas de oferta e procura entre atores anônimos, mas em um conjunto de ações estritamente imersas em redes concretas de relações sociais (GRANOVETTER, 2002). Portanto, as redes sociais podem explicar, conforme Mizruchi (2009), a influência estrutural de grupos na ação econômica. 
Segundo Raud-Mattedi (2005b), a sociologia contemporânea pode buscar caminhos para aprofundar a reflexão a respeito dos mecanismos pelos quais as estruturas de redes permitem a emergência e a manutenção da confiança. Afirmar simplesmente que a confiança no mercado decorre das relações pessoais é esquecer o papel das normas jurídicas e morais, bem como esquecer que, se muitas relações econômicas passam por relações pessoais, também muitas não passam por elas, e isso não implica obrigatoriamente mais oportunismo (RAUD-MATTEDI, 2005b).

Como apresentado na seção anterior, observamos que aspectos sociais como o efeito moral da solidariedade para mercados de produção territorializados podem ser compreendidos como estruturas socioeconômicas de redes interorganizacionais. E nesse sentido, portanto, a rede social é um conceito que complementa a discussão de Durkheim (I999), especificamente da estrutura das sociedades industriais, definindo uma tipologia para as relações sociais, que para este artigo constitui uma categoria analítica utilizada de forma conjunta com o processo de divisão do trabalho e que reafirma a importância da coesão, solidariedade, confiança e regulação coletiva. Um dos aspectos importantes que a perspectiva de rede retoma na discussão da sociologia econômica de Durkheim (I999) é o papel da confiança entre os atores, principalmente como forma social objetiva de regulação das partes. Para Granovetter (I973), a confiança é estimulada e a desconfiança é desestimulada quando as ações no mercado estão inseridas em estruturas mais amplas de relações pessoais e intercâmbios sociais.

O capital social dessas redes seria uma consequência das relações de confiança, portanto uma síntese das relações micro e macrossociais, em que são considerados laços fortes e fracos, com foco na formação e no desenvolvimento de redes sociais, observando-se nestas as influências tanto individuais quanto coletivas para a construção social dos mercados. Para Bourdieu (2002), o capital social é uma integração de recursos atuais ou potenciais ligados pela posse de redes duráveis, mais ou menos institucionalizadas, por meio de relacionamentos mútuos de conhecimento e reconhecimento de membros de grupos (étnico, familiar, gênero, classe, geográfico etc.), a partir de vários sensos ou de credenciais sociais. Ou seja, as redes de relacionamento produzem estratégias de investimentos, individuais ou coletivas, conscientes ou inconscientes, apontando para o estabelecimento ou a reprodução social de relacionamentos, que são usuais no curto ou no longo prazos, podendo ser internalizado.

A evolução econômica e seus problemas demandam soluções institucionalizadas socialmente. Relações sociais institucionalizadas em arranjos ou moralidades generalizadas, que são responsabilidades da produção e também da vida econômica. A estrutura do mercado, tanto no interior de uma indústria, em sua cadeia de produção ou em determinado território, tanto do lado da demanda 
quanto do lado do fornecimento de insumos, pode ser compreendida pelos custos de transações que demandam estruturas organizacionais e de grupos sociais, portanto os efeitos morais decorrentes de relacionamentos sociais de determinados grupos têm reflexos econômicos em redes interorganizacionais. De acordo com Granovetter (2002), a estrutura do mercado se materializa em redes de organizações geradas por oportunidades de transações, que não podem ser compreendidas em uma corporação única, pois o mercado se estrutura em integrações verticais e horizontais, que consideram, inclusive, as estruturas intermediárias entre as organizações que viabilizam sua integração. O comportamento humano nesse contexto socioeconômico não pode ser tratado simplesmente como relação interpessoal e não social do ponto de vista da ação humana (GRANOVETTER, 2002). Portanto, vale ressaltar que as redes sociais, a geração e o contexto cultural têm influência central no mercado, diante de seus problemas e imperfeições (SMELSER; SWEDBERG, I994).

\section{CONSIDERAÇÕES FINAIS}

O crescimento e adensamento das sociedades podem ser analisados como causa determinante, que permite mais que requer maior divisão do trabalho que na sociedade atual se expande entre organizações que concentram seus sistemas produtivos em determinados territórios para alcançar suas vantagens competitivas para o mercado global. A divisão do trabalho social une ao mesmo tempo em que opõe e faz convergir as atividades que diferenciam e aproximam aqueles que se separam. A diferenciação não pode ter determinado essa aproximação, e é necessário que os indivíduos sejam solidários e a sintam, isto é, pertençam a uma mesma sociedade. As diversas partes do agregado, por cumprirem funções diferentes, não podem ser facilmente separadas. Esses grupos sociais em que a solidariedade é preponderante são constituídos não por uma repartição de segmentos similares e homogêneos, mas por um sistema de órgãos diferentes, e cada um deles tem papel especial e é formado, ele próprio, de partes diferenciadas que podem ser compreendidas tanto intraorganizacional como interorganizacionalmente.

Os conceitos durkheimianos sobre a DTS ajudam a compreender a estratégia de expansão atual da organização industrial com a especialização de territórios por meio de redes interoganizacionais. Para a economia, o território é encarado, essencialmente, como agregado de atores que, em dadas circunstâncias, podem comportar-se como ator coletivo. Nesse sentido, o território nunca cria redes diretamente, mas favorece a constituição de relações entre atores socialmente 
próximos. Ao mesmo tempo, as redes de relações locais interagem com outros níveis territoriais, por meio da interação de atores que pertencem, simultaneamente, a uma rede local e uma supralocal. Os territórios ligam-se à economia global por promoverem a própria especialização, portanto permitem a difusão de estratégias e escolhas destinadas a promover e fortalecer os sistemas ou agrupamentos presentes com a geração de valor econômico. No entanto, nos territórios o desafio estratégico é de natureza organizacional, que envolve a coordenação de atores e de seus princípios de ação e comunicação.

As redes sociais, de forma específica, como a sociologia econômica, de forma geral, constituem um tema de relevância por buscar compreender o fato social não a partir da liberdade individual, mas da ação coletiva que se coloca às vontades individuais. Ação coletiva imersa na ação dos indivíduos e que garante também a sua existência e que permite observar as estratégias tanto de grupos individuais como organizacionais. As implicações sociológicas na estratégia de organizações podem ser compreendidas a partir de fatos sociais importantes como a solidadriedade, coesão e densidade moral. As aglomerações produtivas decorrem, muitas vezes, de estratégias competitivas globais, por meio de reflexões com o auxílio teórico da sociologia econômica, que nos permite identificar questões relacionadas à racionalidade da ação coletiva e das redes sociais.

A divisão do trabalho social de Durkheim (I999) conserva, ainda hoje, indubitável importância histórica e metodológica, com uma abordagem de grandes tendências evolutivas do desenvolvimento da sociedade moderna, como o desenvolvimento do individualismo e o papel da regulamentação (valores e normas) e dos grupamentos profissionais. A cooperação para perspectiva durkheimiana tem como ênfase a internalização de valores que induzem a concordância de normas e a produtividade decorrentes da especialização, o que é apenas uma consequência necessária, um reflexo econômico do fenômeno social. A especialização tem uma utilidade produtiva, com a função social de viabilizar a sobrevivência humana nas novas condições de existência da sociedade industrial.

Uma contribuição importante da perspectiva Durkheimiana são os aspectos solidários do mercado. Para Durkheim (I999), o mercado não é composto somente por relações econômicas de livre troca entre os indivíduos. A coesão social está presente nas relações de competição econômica que geram conflitos, especializam o trabalho e satisfazem as necessidades individuais.

O conceito de redes sociais auxilia a compreensão atualmente da coesão social necessária para o desenvolvimento econômico de sistemas produtivos territorializados. O desenvolvimento das redes compõe a dinâmica social do desenvolvimento local de territórios. Portanto, podemos constatar que políticas públicas de desenvolvimento regional ou local buscam promover e articular atores em arranjos produtivos locais. Entretanto, a explicação até o momento tem sido para 
uma perspectiva utilitarista em detrimento de uma análise evolutiva e funcionalista na qual a abordagem durkheimiana pode jogar luz. Principalmente com a compreensão das relações sociais fundamentais que seriam condições essenciais para que o aumento e a densidade moral dessas aglomerações gerassem solidariedade em vez de conflitos de interesses entre esses empreendimentos, valorizando assim suas individualidades e aumentando a coesão social desses APL.

O Estado promotor das políticas públicas de desenvolvimento de territórios é um ator com interesses coletivos, mas este não pode perder de seu campo de visão sua relação com o indivíduo, que deve estar inserido no mundo da vida, que proporciona a base da solidariedade, confiança e identidade. Os APL governados por associações de desenvolvimento territorial podem ter um papel importante de ligação entre o Estado e o indivíduo, diante da realidade da organização industrial do século XXI. Estes devem se firmar como organizações que interagem com indivíduos e outras organizações para o alcance de objetivos comuns da sociedade e do grupo de interesses individuais e coletivos que representem.

Entretanto, mesmo considerando esses aspectos tanto conceituais como empíricos, existe um longo caminho na compreensão social da economia, a ser percorrido com o desenvolvimento de métodos históricos comparativos que possibilitem incluir categorias analíticas, como a família e grupos sociais diversos, como fenômenos socioeconômicos que merecem ser evidenciados a partir de seus reflexos na realidade organizacional e econômica.

\section{DIVISION OF SOCIAL WORK AND LOCAL PRODUCTIVE ARRANGEMENTS: ECONOMIC REFLECTIONS OF THE MORAL EFFECTS OF INTERORGANIZATIONAL NETWORKS}

\section{ABSTRACT}

This article uses a theoretical framework that highlights social factors, specifically the division of labor, which act directly on the effectiveness of organizations through cohesion and solidarity. However, this reading of the economic reality has not been utilized to its fullest for understanding the social embeddedness of interorganizational networks on spacial distribution, i. e., local productive arrangements. It can be noticed that a key competitive feature, referred to as present within the corporate discourse and even economic development policies is the need from companies to act jointly, associated in certain territories, wheth- 
er industrial districts, regions, counties or cities. Therefore, the crowding is a real possibility for business development from organizational structures based on partnership, complementarity, sharing, exchange and mutual assistance, which have in the networks, which also compose the social structure of markets and reinforce the discussion of sociology that competition also leads to solidarity. The individual economic actions are not free from structural pressures and capable of being interpreted in the purely mechanical and additive aggregation. Structural pressures that weigh on economic action cannot be reduced to the requirements specified at a given moment in time, in cash or in the immediate economic instability of the interactions. The economic interests of the market are for the new economic sociology immersed in personal networks and social groups. The market, therefore, is not composed by isolated organizations, such as models of perfect competition in economics, but organizational clusters, that form a social structure.

\section{KEYWORDS}

Local production; Territorial production; Division of social work; Social relations; Social structure.

\section{DIVISIÓN DE TRABAJO SOCIAL Y ARREGLOS PRODUCTIVOS LOCALES: REFLEXOS ECONOMICOS DE LOS EFECTOS MORALES DE LAS REDES INTER- ORGANIZACIONALES}

\section{RESUMEN}

Este artículo utiliza un marco teórico que pone de relieve los factores sociales, específicamente la división del trabajo, que actúan directamente sobre la eficacia de las organizaciones a través de la cohesión y la solidaridad. Sin embargo, esta lectura de la realidad económica no se ha utilizado al máximo para la comprensión de la integración social de las redes interinstitucionales en la distribución espacial, es decir, arreglos productivos locales. Se puede observar que algunas características clave de la competencia, que se refiere a la presente como en el discurso empresarial y las políticas de desarrollo incluso económico es la necesidad de las empresas a actuar de manera conjunta, asociada en algunos territorios, si los distritos industriales, regiones, condados o ciudades. Por lo tanto, el 
hacinamiento es una posibilidad real para el desarrollo empresarial de las estructuras de organización basado en la cooperación, la complementariedad, la distribución, intercambio y asistencia mutua, que tienen en las redes, que también componen la estructura social de los mercados y reforzar el análisis de sociología que la competencia conduce también a la solidaridad. Las acciones económicas individuales no están libres de las presiones estructurales y capaz de ser interpretado a la agregación puramente mecánica y aditivos. presiones estructurales que pesan sobre la actividad económica no puede reducirse a los requisitos especificados en un momento dado en el tiempo, en dinero o en la inestabilidad económica inmediata de las interacciones. Los intereses económicos del mercado son para la nueva sociología económica inmersos en redes personales y los grupos sociales. El mercado, por lo tanto, no está compuesto de organizaciones aisladas, como los modelos de competencia perfecta en la economía, sino de grupos de organización que forman una estructura social.

\section{PALABRAS CLAVE}

Producción local; Producción territorial; División de trabajo social; Relaciones sociales; Estructura social.

\section{REFERÊNCIAS}

ABRAMOVAY, R. Anticapitalismo e inserção social dos mercados. Tempo Social - Revista de Sociologia da USP, v. 2I, n. I, p. 65-87, jun. 2009.

AMATO NETO, J. Redes de cooperação produtiva e clusters regionais: oportunidades para as pequenas e médias empresas. São Paulo: Atlas, Fundação Vanzolini, 2000.

BAIARDI, A.; LANIADO, R. N. Redes e associativismo em uma sociedade globalizada: novas atitudes da classe empresarial na Bahia. Caderno CRH, Salvador, v. I9, n. 46, p. III-I2I, jan./abr. 2006. BOURDIEU, P. The forms of capital. In: BIGGART, N. (Org.). Readings in economic socilogy. Malden, MA: Blackwell, 2002. p. 280-29I.

BOURDIEU, P. O campo econômico. Política \& Sociedade, v. I, n. 6, p. 15-57, abr. 2005 a.

BOURDIEU, P. The social structures of the economy. Cambridge: Polity Press, 2005b.

CASSIOLATO, J. E.; LASTRES, H. M. M. O enfoque em sistemas produtivos e inovações locais. In: FISCHER, T. (Org.). Gestão do desenvolvimento e poderes locais: marcos teóricos e avaliação. Salvador: Casa da Qualidade, 2002. p. 6I-76.

CONTI, S. Espaço global versus espaço local: perspectiva sistêmica do desenvolvimento local. In: DINIZ, C. C.; LEMOS, M. B. (Org.). Economia e território. Belo Horizonte: Editora UFMG, 2005. p. $209-252$.

CROCCO, M. A.; GALINARI, R.; SANTOS, F.; LEMOS, M. B.; SIMÕES, R. Metodologia de identificação de aglomerações produtivas locais. Nova Economia, v. I6, n. 2, p. 2II-24I, 2006. 
DINIZ, C. C.; SANTOS, F.; CROCCO, M. A. Conhecimento, inovação e desenvolvimento regional/ local. In: DINIZ, C. C.; CROCCO, M. (Org.). Economia regional e urbana: contribuições teóricas recentes. Belo Horizonte: Editora UFMG, 2006. p. 87-I22.

DURKHEIM, É. Da divisão do trabalho social. 2. ed. São Paulo: Martins Fontes, I999.

GEREFFI, G. The organization of buyer-driven global commodity chains: how U.S. retailers shape overseas production. In: GEREFFI, G.; KORZENIEWICZ, M. Commodity chains and global capitalism. London: Praeger, I994. p. 95-I22.

GEREFFI, G.; KORZENIEWICZ, M.; KORZENIEWICZ, R. P. Introduction: global commodity chains. In: GEREFFI, G.; KORZENIEWICZ, M. Commodity chains and global capitalism. London: Praeger, I994. p. I-I4.

GRANOVETTER, M. The strength of weak ties. American Journal of Sociology, v. 78, n. 6, p. I360I380, May I973.

GRANOVETTER, M. The sociological and economic approches to labor market analysis: a social structural view. In: GRANOVETTER, M.; SWEDBERG, R. (Ed.). The sociology of economic life. Boulder: Westview Press, I992. p. 233-264.

GRANOVETTER, M. Business groups. In: SMELSER, N.; SWEDBERG, R. (Ed.). The handbook of economic sociology. Princeton, NY: Princeton University Press, I994. p. 453-475.

GRANOVETTER, M. Economic action and social structure: the problem of embeddedness. In: BIGGART, N. (Ed.). Readings in economic sociology. Malden, MA: Blakwell, 2002. p. I54-I67.

HADDAD, P. R. Força e fraqueza dos municípios de Minas Gerais. Cadernos BDMG, n. 8, p. 7-46, abr. 2004 .

KORZENIEWICZ, M. Commodity chains and marketing strategies: nike and the global athletic footwear industry. In: GEREFFI, G.; KORZENIEWICZ, M. Commodity chains and global capitalism. London: Praeger, I994. p. 247-265.

LEMOS, M. B. Desenvolvimento econômico e a regionalização do território. In: DINIZ, C. C.; CROCCO, M. (Org.). Economia regional e urbana: contribuições teóricas recentes. Belo Horizonte: Editora UFMG, 2006. p. I73-I94.

LIN, N. Building a network theory for social capital. In: LIN, N.; COOK, K.; BURT, R. Social capital: Theory and research. New York: Aldine de Gruyter, 200I. p. 3-29.

MARX, K. O processo de produção do capital. In: MARX, K. O capital: crítica da economia política. Io. ed. São Paulo: Difusão Editorial, I985. v. I, p. 370-422.

MIZRUCHI, M. S. Análise de redes sociais: avanços recentes e controvérsias atuais. In: MARTES, A. C. B. (Org.). Redes e sociologia econômica. São Carlos: EdUFSCar, 2009. p. I3I-I59.

PIORE, M. J.; SABEL, C. F. The second industrial divide: possibiliteis for prosperity. USA: BasicBooks, I984.

POLANYI, K. A grande transformação: as origens de nossa época. 8. ed. Rio de Janeiro: Campus, 2000. PUTNAM, R. D. Comunidade e democracia: a experiência da Itália moderna. 4. ed. Rio de Janeiro: Editora FGV, 2005.

RAUD, C. Bourdieu e a nova sociologia econômica. Tempo Social, v. I9, n. 2, p. 203-232, nov. 2007.

RAUD, C. Dimensões da sociologia econômica no Brasil. In: MONDADORE, A. P. C. et al. (Org.). Sociologia econômica e das finanças: um projeto em construção. São Carlos: EdUFSCar, 2009. p. 345-364. 
RAUD-MATTEDI, C. A construção social do mercado em Durkheim e Weber: análise do papel das instituições na sociologia econômica clássica. Revista Brasileira de Ciências Sociais, v. 20, n. 57, p. I27-208, fev. 2005a.

RAUD-MATTEDI, C. Análise crítica da sociologia econômica de Mark Granovetter: os limites de uma leitura do mercado em termos de redes e imbricação. Revista Política \& Sociedade, n. 6, p. 59-82, abr. 2005 b.

RAYNOLDS, L. T. Institucionalizing flexibility: a comparative analysis of fordist and post-fordist models of third world agro-export production. In: GEREFFI, G.; KORZENIEWICZ, M. Commodity chains and global capitalism. London: Praeger, I994.

SMELSER, N.; SWEDBERG, R. The sociological perspective on the economy. In: SMELSER, N.; SWEDBERG, R. (Org.). The handbook of economic sociology. Princeton: Princeton University Press, I994. p. 3-26.

SMITH, A. A riqueza das nações. São Paulo: Nova Cultural, I996. p. 65-80. Coleção Os economistas. SOUZA, Y. S.; SOUZA, K. G. A. de. Relações cooperativas entre pequenas e médias empresas: um estudo de caso no arranjo coureiro calçadista do Vale dos Sinos (RS-Brasil). In: ENCONTRO DE ESTUDOS ORGANIZACIONAIS (ENEO), 3., 2004, São Paulo. Anais... São Paulo: Eneo, 2004. SUZIGAN, W.; CERRÓN, A. P. M.; DIEGUES JUNIOR, A. C. Localização, inovação e aglomeração: o papel das instituições de apoio às empresas no Estado de São Paulo. São Paulo em Perspectiva, v. I9, n. 2, p. 86-100, abr./jun. 2005.

SUZIGAN, W.; GARCIA, R.; FURTADO, J. Clusters ou sistemas locais de produção e inovação: identificação, caracterização e medidas de apoio. 2002. Disponível em: <http://geein.fclar.unesp.br/ atividades/pesquisacluster/IEDI_20030516_clusters.pdf>. Acesso em: 7 fev. 2009.

SUZIGAN, W.; GARCIA, R.; FURTADO, J. Sistemas locais de produção/inovação: metodologia para identificação, estudos de casos e sugestões de políticas. In: DINIZ, C. C.; LEMOS, M. B. Economia e território. Belo Horizonte: Editora UFMG, 2005. p. 287-320.

SUZIGAN, W.; GARCIA, R.; FURTADO, J. Estruturas de governança em arranjos ou sistemas locais de produção. Gestão \& Produção, v. I4, n. 2, p. 425-439, maio/ago. 2007.

SWEDBERG, R. Markets as social structures. In: SMELSER, N.; SWEDBERG, R. (Ed.). The handbook of economic sociology. Princeton: Princeton University Press, I994. p. 255-282.

SWEDBERG, R. Sociologia econômica: hoje e amanhã. Tempo Social, v. I6, n. 2, p. 7-34, nov. 2004. SWEDBERG, R.; GRANOVETTER, M. Introduction. In: GRANOVETTER, M.; SWEDBERG, R. (Ed.). The sociology of economic life. Boulder: Westview Press, I992. p. I-26. 